\title{
Socio-demographic and psychological determinants of exclusive breastfeeding after six months postpartum - a Polish case-cohort study
}

\author{
Karolina Maria Maliszewska ${ }^{1}$, Mariola Bidzan², \\ Małgorzata Świątkowska-Freund ${ }^{1}$, Krzysztof Preis ${ }^{1}$ \\ ${ }^{1}$ Medical University of Gdansk, Department of Obstetrics, Gdansk, Poland \\ 2University of Gdansk, Institute of Psychology, Gdansk, Poland
}

\begin{abstract}
Objectives: The purpose of this study was to explore the socio-demographic and psychological factors connected with exclusive breastfeeding after 6 months postpartum.

Material and methods: A total of 251 women filled in questionnaires in the first week postpartum, then again after 3 and 6 months. The questionnaires included socio-demographic and medical questions, as well as psychological tools: the NEO-FFI Personality Inventory, the Berlin Social Support Scales (BSSS), and the Edinburgh Postnatal Depression Scale (EPDS). Further detailed questions concerning breastfeeding were relevant to this study.

Results: The rate of exclusive breastfeeding after 6 months was $39.68 \%$. It was found that exclusive breastfeeding was most strongly connected with attending prenatal classes ( $\mathrm{ORa}=2.84, \mathrm{Cl} 1.18-6.87, \mathrm{p}=0.01)$, formula supplementation after 3 months $(\mathrm{ORa}=0.01, \mathrm{Cl} 0.002-0.08, \mathrm{p}<0.001)$ and the mother's subjective satisfaction with feeding the infant after 3 months $(\mathrm{ORa}=1.44, \mathrm{Cl} 1.01-2.06, \mathrm{p}=0.04)$. No other psychological (as far as personality, social support or risk of postpartum depression are concerned), demographic or medical factors were significant, except for those pertaining strictly to breastfeeding. Conclusions: The prevalence of exclusive breastfeeding in Poland is unsatisfactory. Women should have easy access to prenatal classes with the most up-to-date knowledge on lactation and be advised against supplementing with formula, whenever possible. This could lead to higher satisfaction with breastfeeding.
\end{abstract}

Key words: breastfeeding, personality, postpartum depression, social support

Ginekologia Polska 2018; 89, 3: 153-158

\section{INTRODUCTION}

In 2003, the World Health Organisation (WHO) issued a report clearly stating that newborns should be exclusively breastfed for the first 6 months of life and then, after the introduction of complementary food, breastfeeding should be maintained up to the age of 2 years or longer, based on the needs of a mother and a child [1]. Polish recommendations are in line with this since 2014 [2].

European rates of breastfeeding are not satisfactory [3]. In Poland in 2002, rates of exclusive breastfeeding at 4 and 6 months were 31\% and 9\% respectively [3]. According to the Central Statistical Office of Poland, in 2014, $87 \%$ of children were breastfed, $13 \%$ were breastfed until 6 months, and $12 \%$ until 1 year old. However, this does not specify exclusivity [4]. Polish studies on small samples report a 98 to $99.4 \%$ rate of initiating breastfeeding, but only $22.4 \%$ exclusively breastfed up to 6 months with $3.7 \%$ breastfeeding exclusively for 6 months $[5,6]$.

Identification of women at risk of early cessation of breastfeeding is considered a health priority.

Such a huge difference between official recommendations and current rates of breastfeeding should be thoroughly investigated. There are papers highlighting the role of caesarean section, and various self-reported concerns such 
as, inter alia, low milk supply, the infant's dissatisfaction with the milk, issues concerning the nutritional value of the milk, or the infant's self-weaning before the age of one [7-9].

The influence of psychological determinants of breastfeeding has also been studied. Personality traits such as neuroticism, agreeableness, and openness to experience are linked with breastfeeding duration [10]. Wagner [11] associated extraversion, openness, and agreeableness with breastfeeding initiation, while in Brown's study [12] extraversion, emotional stability (low neuroticism), and conscientiousness were significant.

Social support, both peer and professional, plays an important role in breastfeeding $[13,14]$. Studies emphasize that mothers find person-centred communication skills and adequate organizational systems to be most supportive [15].

In the literature, the link between breastfeeding and postpartum depression is bidirectional, although still unclear. Reports suggest that a mother's depressive symptomatology may result in worse breastfeeding outcomes or duration, while breastfeeding may be protective against depression [16-18].

\section{Objectives}

The aim of this study was to investigate the influence of socio-demographic and psychological factors, such as personality, social support, or risk for postpartum depression, on exclusive breastfeeding after 6 months postpartum. There are few articles combining these data in the context of breastfeeding in this timeframe in Eastern Europe.

\section{MATERIAL AND METHODS}

This study was a case-cohort study, a secondary objective of a prospective cross-sectional research project on postpartum mood disorders.

Patients in the first week after childbirth were recruited in the Clinic between May, 2013 and June, 2014. Each patient received information on the purpose and structure of the investigation and provided formal written consent. The inclusion criteria were that participants were literate, aged over 18 , and could be contacted by email or post. We used the following exclusion criteria: preterm childbirth (before week 37.0), death of the child, the child requiring special parental and medical care, serious medical causes of ablactation, the use of certain drugs (steroids, azathioprine, sertraline, paroxetine), or current mental disorder as the study does not focus on those special circumstances. Participants were asked to fill out a questionnaire in their first week postpartum, and in 3 and 6 months after delivery. They received detailed questions concerning breastfeeding in the last phase. We chose to use the term "almost-exclusively breastfeeding" as guidelines suggest that additional meals be introduced after 6 months, while lactation should be continued. Mothers were asked whether any supplementary formula had been introduced and was still used. If the answer was "no," the woman was qualified to the "almost-exclusive breastfeeding" group. A "yes" answer qualified a mother to the "non-exclusive breastfeeding" group. Of the 479 patients recruited, 59 met the exclusion criteria and a further 143 were lost in follow-up (did not answer after the third month). We sent 277 requests after 6 months, and received 251 answers, giving a $90.1 \%$ participation rate (59.8\%, when including those lost in follow-up).

A questionnaire, created for this study, concerning socio-demographic and medical status, was used alongside a battery of standardized psychological tests: the NEO-FFI Personality Inventory, the Berlin Social Support Scales (BSSS), and the Edinburgh Postnatal Depression Scale (EPDS).

The NEO-FFI test consists of five scales: neuroticism (N), extraversion $(\mathrm{E})$, openness to experience $(\mathrm{O})$, agreeableness $(A)$, and conscientiousness (C). Raw points are converted into a standardized 10-point scale of sten scores. As required, we purchased individual forms specifically for use in the study. Psychometric values have been proven to be satisfactory (ie, internal consistency coefficients of subscales $\geq 0.70$ ) [19]. The BSSS measures the following dimensions of social support: perceived available support, need for support, support seeking, currently received support, and protective-buffering. The final result is the arithmetic mean of a scale. Its psychometric features such as Cronbach's alpha (0.71 to 0.90) and validity are satisfactory [20]. The EPDS consists of 10 questions and is used for identifying risk of postpartum depression [21, 22]. In this study, we assumed a score of 13 as the cut-off point. This limit yields satisfactory sensitivity (84.2\% to $93.9 \%)$ and specificity (75.2\% to $76.7 \%)$. The Cronbach's alpha is on the level of 0.87 to 0.88 [23]. Data assessed by the patient (satisfaction with feeding of the infant) was measured on a 11-point scale similar to the Numerical Rating Scale (NRS) with 0 as the worst level and 10 as the best one. The questionnaires after 3 and 6 months consisted of EPDS and questions concerning medical status and details about feeding the infant (such as continuation of breastfeeding, number of breastfeedings per day, any supplementing with formula, duration of breastfeeding, and satisfaction with feeding the baby).

A statistical analysis was conducted with the use of STATISTICA 12.0 software. We used the following tests: the Student t-test, the Mann-Whitney U-test, and the $\mathrm{Chi}^{2}$ test. A single-factor repeated-measures analysis of variance was conducted to compare the effect of time of response on the assessment of feeding the infant, using first, second, and third responses as conditions. The Friedman test (nonparametric test for repeated-measures) was conducted to compare the effect of time of response to any breastfeeding rate. 
Univariate and multivariate logistic regression models were used to investigate predictors of exclusive breastfeeding after 6 months.

The study was approved by the institutional Board of Ethics (NKEBN/531/2011-2012).

\section{RESULTS}

The average mother was 30.42 years old (range: 19 to 46 ). These women gave birth in the $39.65^{\text {th }}$ week of pregnancy on average (range: 37 to 42.0), most often by vaginal birth (75\%). The most common place of residence in our sample was a city with more than 100,000 inhabitants (68.65\%). Most of these women had higher education (82.14\%) and were employed (94.05\%). They were most often married $(81.75 \%)$ and primiparous (60.32\%). Nine patients (3.57\%) had not yet introduced solids into the infant's diet after 6 months.

The patients responded to the questionnaires as follows: an average of 2.52 (range 0 to 13, SD 1.75) days after childbirth, then 14.20 weeks after childbirth (range 11.57 to 26.88, SD 1.46), and then 27 weeks after childbirth (range 25.05 to 34.86 , SD 1.58).

The rate of breastfeeding (both exclusively and partially) was calculated as follows: $87.30 \%$ (220 patients) in the first week postpartum, $75.79 \%$ (191 patients) - three months postpartum, and $63.10 \%$ (159 patients) six months postpartum. The level of satisfaction with feeding the infant (in a group of 238 patients) was respectively 6.57 points (SD 2.88) in the first week, 8.41 points (SD 6.45) after 3 months and 8.60 points (SD 2.31) 6 months postpartum.

After the first six months postpartum, 100 patients breastfed exclusively - a rate of $39.68 \%$. Of those, 23 mothers (9.13\%) achieved it even though supplementary formula had been used at some point. There were 57 women who breastfed partially (22.61\%), while 89 fed the infant with formula only (35.32\%). In these cases, breastfeeding was ceased during the $12^{\text {th }}$ week postpartum $(11.94$, SD 7.49$)$ on average.

The intergroup differences and univariate analysis of socio-demographic and medical factors are shown in Table 1. Attendance of prenatal class, any breastfeeding in the first week postpartum, higher satisfaction with feeding the infant in the first week postpartum and after 3 months, as well as more frequent breastfeeding per day after 3 months increase the chance of almost-exclusive breastfeeding after six months postpartum. Any breastfeeding after 3 months could not be analysed as no patient returned to exclusive breastfeeding after ceasing breastfeeding after 3 months. Formula supplementation after 3 months reduces the chance of almost-exclusive breastfeeding. Sex of the newborn, supplementing with formula in the first month, and frequency of breastfeeding during the first week postpartum were on the threshold of statistical significance.
Next, we analysed psychological data in the context of almost-exclusive breastfeeding after 6 months. We found no statistical significance between almost all scales of the NEO-FFI, BSSS, EPDS and exclusive breastfeeding (Tab. 2 and 3). Almost-exclusive breastfeeding after 6 months postpartum was not affected by personality (as measured by the $\mathrm{NEO}-\mathrm{FFI}$ ), social support of the closest person in the first postnatal week (BSSS), or depressive symptoms measured with EPDS.

Finally, we established a model of factors associated with almost-exclusive breastfeeding after 6 months using a multivariate logistic regression analysis. Attendance at prenatal classes, formula supplementation in the fourth month, and satisfaction with feeding the infant in the fourth month are significant predictors of almost-exclusive breastfeeding (Tab. 4). The model was found to be significant $\left(x^{2}=108.16\right.$, $d f=22, p<0.001)$, and all predictors explained $41.2 \%$ of the dependent variable (pseudo $\mathrm{R}^{2}=0.415$ ).

\section{DISCUSSION}

Rates of breastfeeding found in the study are high compared to results from the literature but is still suboptimal $[5,6,24]$. Most socio-demographic and psychological factors were not significant, except for attendance at prenatal classes, formula supplementation, and satisfaction with feeding the infant after 3 months.

In Poland, prenatal class is one of the easiest ways for a mother to learn about pregnancy, labour, and breastfeeding. Taking part in such groups is beneficial for further breastfeeding as they provide basic knowledge such as current medical recommendations. This is consistent with the available literature. MacFadden [25] highlights that organised support helps women to breastfeed longer. It has also been shown that knowledge about recommendations about exclusive breastfeeding leads to women breastfeeding for longer [26].

It was found that satisfactory breastfeeding without formula supplementation is a factor promoting almost-exclusive breastfeeding after 6 months. This is consistent with a Cochrane Review [27], The introduction of formula causes down-regulation of lactation [28]. Therefore, if the mother introduces formula too soon and without clear indications, it may result in shorter exclusive breastfeeding. Maternal confidence seems to be important as well. Although satisfaction with feeding the infant was assessed with the use of a subjective 0 to 10 scale, its simplicity emphasizes the role of the mother's perception of the current feeding situation.

In contrast to previous research, this study did not find links between psychological data and almost-exclusive breastfeeding after 6 months. A closer look at some papers may show methodological differences such as different tools or sample size responsible for this inconsistency [11, 12]. 
Table 1. Sample characteristics of women almost-exclusive and non-exclusive breastfeeding after 6 months postpartum.

\begin{tabular}{|c|c|c|c|c|c|c|}
\hline \multirow{3}{*}{ Parity } & \multirow[b]{3}{*}{ Primipara } & $\begin{array}{l}\text { Almost-exclusive } \\
\text { breastfeeding } \\
n=100\end{array}$ & $\begin{array}{l}\text { Non-exclusive } \\
\text { breastfeeding } \\
n=151\end{array}$ & \multicolumn{3}{|c|}{$\begin{array}{l}\text { Univariate model of logistic } \\
\text { regression }\end{array}$} \\
\hline & & \multicolumn{2}{|c|}{ Mean (SD) or $n(\%)$ of subgroup } & ORc & $95 \% \mathrm{Cl}$ & p \\
\hline & & $55(55 \%)$ & 97 (64.24\%) & 0.68 & $0.41-1.14$ & 0.14 \\
\hline & Multipara & $45(45 \%)$ & $54(35.76 \%)$ & 1 & & \\
\hline \multirow[t]{2}{*}{ Delivery mode } & Caesarean section & $19(19 \%)$ & $43(28.48 \%)$ & 0.59 & $0.32-1.09$ & 0.09 \\
\hline & Vaginal & 81 (81\%) & 108 (71.52\%) & 1 & & \\
\hline Delivery time (weeks of pregnancy) & & $39.88(1.09)$ & $39.55(1.04)$ & 1.25 & $0.98-1.60$ & 0.07 \\
\hline Prenatal classes before pregnancy ${ }^{a}$ & & $59(59 \%)$ & $69(45.70 \%)$ & 1.71 & $1.02-2.86$ & 0.04 \\
\hline \multirow[t]{2}{*}{ Neonatal sex $(n=232)$} & Boy & $42(46.67 \%)$ & $48(53.33 \%)$ & 0.59 & $0.34-1.00$ & 0.05 \\
\hline & Girl & $48(53.33 \%)$ & $57(40.14 \%)$ & 1 & & \\
\hline \multirow[t]{4}{*}{ Breastfeeding (any) ${ }^{a}$} & 1 Yes & $93(93 \%)$ & $127(84.11 \%)$ & 2.51 & $1.03-6.10$ & 0.04 \\
\hline & No & $7(7 \%)$ & 24 (15.89\%) & 1 & & \\
\hline & $\begin{array}{c}3 \text { Yes } \\
(n=250)\end{array}$ & $99(100 \%)$ & $92(60.93 \%)$ & * & & \\
\hline & No & $0(0 \%)$ & $59(39.07 \%)$ & & & \\
\hline \multirow[t]{2}{*}{ Supplementation with formula ${ }^{a}$} & $\begin{array}{c}1 \text { Yes } \\
(n=90)\end{array}$ & $10(27.03 \%)$ & $25(47.17 \%)$ & 0.42 & $0.17-1.04$ & 0.05 \\
\hline & $\begin{array}{c}3 \text { Yes } \\
(n=208)\end{array}$ & $2(2.63 \%)$ & $85(64.39 \%)$ & 0.01 & $0.003-0.06$ & 0.00 \\
\hline \multirow[t]{2}{*}{ Number of breastfeedings per day } & $\begin{array}{c}1 \\
(n=212)\end{array}$ & $8.13(2.57)$ & $7.44(2.56)$ & 1.11 & $1.00-1.24$ & 0.05 \\
\hline & 3 & $8(1.96)$ & $7.18(2.45)$ & 1.19 & $1.04-1.38$ & 0.01 \\
\hline \multirow[t]{2}{*}{ Satisfaction with feeding the infant ${ }^{b}$} & $\begin{array}{c}1 \\
(n=238)\end{array}$ & $7.24(2.66)$ & $6.09(2.93)$ & 1.16 & $1.05-1.28$ & 0.003 \\
\hline & $\begin{array}{c}3 \\
(n=237)\end{array}$ & $9.36(0.96)$ & $7.74(2.74)$ & 1.76 & $1.38-2.24$ & 0.00 \\
\hline
\end{tabular}

ORc - crude odds ratio, $\mathrm{Cl}$ - confidence interval, ${ }^{\mathrm{a}}$ - yes $/$ no answer, 1 - in the first week postpartum, 3 - after 3 months postpartum, ${ }^{*}$ - not calculated, ${ }^{\mathrm{b}}-\mathrm{scale}$ 0 (worst) -10 (best)

Table 2. Psychological characteristics: personality characteristics as measured by NEO-FFI, and social support (BSSS) of women almost-exclusive and non-exclusive breastfeeding after 6 months postpartum

\begin{tabular}{|c|c|c|c|c|c|c|c|}
\hline & & $\begin{array}{l}\text { Almost-exclusive } \\
\text { breastfeeding }\end{array}$ & $\begin{array}{l}\text { Non-exclusive } \\
\text { breastfeeding }\end{array}$ & \multirow[b]{2}{*}{$\mathbf{p}$} & \multicolumn{3}{|c|}{$\begin{array}{l}\text { Univariate model of logistic } \\
\text { regression }\end{array}$} \\
\hline & & \multicolumn{2}{|c|}{ Mean (SD) } & & ORc & $95 \% \mathrm{Cl}$ & $\mathbf{p}$ \\
\hline \multirow{5}{*}{ NEO-FFI } & N & $3.97(2.00)$ & $4.11(3.97)$ & 0.71 & 0.96 & $0.84-1.10$ & 0.57 \\
\hline & $\mathrm{E}$ & $5.95(1.67)$ & $6.09(5.95)$ & 0.62 & 0.96 & $0.84-1.10$ & 0.56 \\
\hline & 0 & $5.65(2.00)$ & $5.17(5.65)$ & 0.07 & 1.13 & $0.99-1.30$ & 0.06 \\
\hline & A & $6.13(2.14)$ & $5.95(6.13)$ & 0.66 & 1.04 & $0.92-1.17$ & 0.51 \\
\hline & C & $6.75(2.15)$ & $7.05(6.75)$ & 0.28 & 0.93 & $0.82-1.06$ & 0.23 \\
\hline \multirow{6}{*}{$\begin{array}{l}\text { BSSS } \\
n=250\end{array}$} & Perceived available support & $3.72(0.34)$ & $3.73(3.72)$ & 0.78 & 0.88 & $0.42-1.84$ & 0.73 \\
\hline & Need for support & $3.04(0.56)$ & $3.01(3.04)$ & 0.77 & 1.12 & $0.71-1.76$ & 0.62 \\
\hline & Support seeking & $2.93(0.58)$ & $2.92(2.93)$ & 0.96 & 1.03 & $0.67-1.58$ & 0.90 \\
\hline & Currently received & $3.77(0.39)$ & $3.81(3.77)$ & 0.89 & 0.74 & $0.38-1.44$ & 0.37 \\
\hline & Satisfaction with support & $3.84(0.55)$ & $3.86(3.84)$ & 0.98 & 0.90 & $0.68-1.19$ & 0.45 \\
\hline & Buffering-protective & $1.84(0.55)$ & $1.8(1.84)$ & 0.56 & 1.13 & $0.72-1.78$ & 0.59 \\
\hline
\end{tabular}

$\mathrm{ORc}$ - crude odds ratio, $\mathrm{Cl}$ - confidence interval, NEO-FFI — Neo-Five Factor Personality Inventory, $\mathrm{N}$ - neuroticism, E - extraversion, $\mathrm{O}$ - openness to experience, A - agreeableness, C - conscientiousness, BSSS - Berlin Social Support Scales 
Table 3. Risk for postpartum depression (EPDS) of women almost-exclusive and non-exclusive breastfeeding after 6 months postpartum

\begin{tabular}{|c|c|c|c|c|c|c|c|}
\hline & & $\begin{array}{l}\text { Almost-exclusive } \\
\text { breastfeeding }\end{array}$ & $\begin{array}{l}\text { Non-exclusive } \\
\text { breastfeeding }\end{array}$ & & \multicolumn{3}{|c|}{$\begin{array}{c}\text { Univariate model of logistic } \\
\text { regression }\end{array}$} \\
\hline & & \multicolumn{2}{|c|}{ N (\%) of subgroup } & p & ORc & $95 \% \mathrm{Cl}$ & p \\
\hline \multirow[t]{3}{*}{$\begin{array}{l}\text { EPDS }>12 \text { points or } \\
\text { self-harm }{ }^{a}\end{array}$} & 1 & $12(12 \%)$ & $21(13.91 \%)$ & 0.66 & 0.84 & $0.39-1.81$ & 0.66 \\
\hline & 3 & $6(6 \%)$ & $8(5.30 \%)$ & 0.81 & 1.14 & $0.38-3.41$ & 0.81 \\
\hline & 6 & $6(6 \%)$ & 11 (7.28\%) & 0.69 & 0.81 & $0.30-2.28$ & 0.69 \\
\hline
\end{tabular}

ORc — crude odds ratio, $\mathrm{Cl}$ - confidence interval, EPDS - Edinburgh Postnatal Depression Scale, ${ }^{a}$ - yes/no answer, 1 - in the first week postpartum, 3 - after 3 months postpartum, 6 - after 6 months postpartum

Table 4. Fully adjusted model. Predictors of almost-exclusive breastfeeding after 6 months in multivariate logistic regression

\begin{tabular}{|l|c|c|c|}
\hline & ORa & Cl & P \\
\hline Attendance at prenatal classes $^{\text {a }}$ & 2.84 & $1.18-6.87$ & 0.02 \\
\hline${\text { Formula supplementation } 3^{a}}^{\text {a }}$ & 0.01 & $0.002-0.08$ & $>0.001$ \\
\hline${\text { Satisfaction with feeding the infant } 3^{b}}^{b}$ & 1.44 & $1.01-2.06$ & 0.04 \\
\hline
\end{tabular}

ORa - adjusted odds ratio, $\mathrm{Cl}$ - Confidence interval, ayes/no answer, ${ }^{\mathrm{b}}$ - self-assessment on a scale $0-10,3$ - after 3 months postpartum

Model adjusted for maternal habitation; education; marriage; risk for postpartum depression at 1 week and 3 months (EPDS $>12$ or self-harm): maternal professional activity; mode of delivery; parity; any breastfeeding within the first week; NEO-FFI scales in stens: neuroticism, extraversion, openness to experience, agreeableness, and conscientiousness; and BSSS scales: social support perceived, needed, seek for, satisfaction with, and currently received

It must be emphasized that a single self-rating test does not confirm a diagnosis of depression - we may speak only about the risk of postpartum depression or depressive symptoms. A psychiatric examination or a standardized tool such as the SCID (The Structured Clinical Interview for DSM-IV Axis I Disorders) is required. Pope [29] questions the relation between breastfeeding and postpartum depression and finds other factors to be significant. Our results on postpartum depression stand in opposition to other literature. In Dennis's review [18], many studies cited use different self-rating methods in different timeframes after childbirth, thus more evidence is needed to draw firm conclusions. In a Croatian prospective study [30], it was found that depressive mood in the first week postpartum was associated with lower rates of exclusive breastfeeding 6 to 9 weeks postpartum. This inconsistency is due to differences in the study.

No association was found between social support from a close person in the first week postpartum and almost-exclusive breastfeeding after 6 months. After 6 months the source of support had no discernible impact. We may suppose that social support should be focused on breastfeeding practice and be available at the appropriate time. Professional support should not be neglected. It should be noted that such programs have been created and have proven to be successful, such as UNICEF/WHO's "Ten steps to successful breastfeeding" or the Baby Friendly Hospital Initiative [1, 31].

This study has several limitations. Firstly, the sample size is not remarkable and is rather homogenous (high education, married, urban), with a relatively high dropout rate.
Some answers were incomplete but were included anyway if they contained crucial information. Several self-report measures were used, which are not always reliable [32] even though they are widely used in studies, especially psychological ones. Some crucial information seems to be missing, such as exclusive breastfeeding in the first and fourth months postpartum, supplementation in the first week, effective breastfeeding indicators (number of feedings per day and per night, number of wet diapers, stools, changes in the baby's weight, etc). The limitation connected with formula introduction is that the "non-exclusive breastfeeding" group contains both mothers feeding partially by breast and those feeding with formula only. However, it would be interesting to see the effect of introducing formula to exclusive breastfeeding, thus transforming it to partial breastfeeding, on further breastfeeding.

For the aforementioned reasons, generalization of this paper's conclusions should be rather cautious. Further carefully-planned studies are crucial for exploring barriers to exclusive breastfeeding after 6 months.

\section{CONCLUSION}

A mother's current breastfeeding practice seems to be the greatest influence on the duration of exclusive breastfeeding. Therefore, we should focus on supplying breastfeeding mothers with appropriate knowledge and adequate support. They should have easy access to prenatal classes to ensure that they are informed about the most recent and accurate data on lactation and that they are advised against unnecessary formula supplementation. This could 
contribute to mothers being more satisfied and, hence, breastfeeding for longer.

\section{REFERENCES}

1. World Health Organization. Global strategy for infant and young child feeding [Internet]. Geneva; 2003. http://apps.who.int/iris/bitstre$\mathrm{am} / 10665 / 42590 / 1 / 9241562218$.pdf?ua $=1 \& u a=1$ (access 2017.08.27).

2. Szajewska H, Socha P, Horvath A, et al. Zasady żywienia zdrowych niemowląt. Zalecenia Polskiego Towarzystwa Gastroenterologii, Hepatologii i Żywienia Dzieci [Nutrition of healthy term infants. Recommendations of the Polish Society for Paediatric Gastroenterology, Hepatology and Nutrition]. Stand Med Pediatr. 2014; 11: 321-338.

3. Cattaneo A, Yngve A, Koletzko B, et al. Promotion of Breastfeeding in Europe project. Protection, promotion and support of breast-feeding in Europe: current situation. Public Health Nutr. 2005; 8(1): 39-46, doi: 10.1079/phn2004660, indexed in Pubmed: 15705244.

4. Piekarzewska M, Wieczorkowski R, Zajenkowska-Kozłowska A. Health status population in Poland in 2014 [Internet]. 2016. http://stat.gov. pl/obszary-tematyczne/zdrowie/zdrowie/stan-zdrowia-ludnosci-polski-w-2014-r-,6,6.html (access 2017.08.28).

5. Zagórecka E, Motkowski R, Stolarczyk A, et al. Karmienie naturalne wżywieniu niemowląt z wybranych miast Polski Centralnej iWschodniej. Pediatr Pol. 2007; 82(7): 538-549, doi: 10.1016/s0031-3939(07)70370-0.

6. Bernatowicz-Łojko U, Wesołowska A, Wilińska M. Udział pokarmu kobiecego w żywieniu dzieci do 2 r. ż. w Polsce na przykładzie wojewódzwta kujawsko-pomorskiego [Share of human milk in feeding children to the second year oflife on the example of Kuyavian-Pomoerianin Voivodeship]in Polish. Stand Med Pediatr. 2012; 9: 285-292.

7. Hobbs AJ, Mannion CA, McDonald SW, et al. The impact of caesarean section on breastfeeding initiation, duration and difficulties in the first four months postpartum. BMC Pregnancy Childbirth. 2016; 16: 90, doi: 10.1186/s12884-016-0876-1, indexed in Pubmed: 27118118.

8. Li R, Fein SB, Chen J, et al. Why mothers stop breastfeeding: mothers' self-reported reasons for stopping during the first year. Pediatrics. 2008; 122 Suppl 2: S69-S76, doi: 10.1542/peds.2008-1315i, indexed in Pubmed: 18829834

9. İsik Y, Dag ZO, Tulmac OB, et al. Early postpartum lactation effects of cesarean and vaginal birth. Ginekol Pol. 2016; 87(6): 426-430, doi: 10.5603/GP.2016.0020, indexed in Pubmed: 27418219.

10. Keller N, Medved V, Armano G. The Influence of Maternal Personality and Risk Factors for Impaired Mother-Infant Bonding on Breastfeeding Duration. Breastfeed Med. 2016; 11: 532-537, doi: 10.1089/bfm.2016.0093, indexed in Pubmed: 27805427.

11. Wagner $C L$, Wagner MT, Ebeling $M$, et al. The role of personality and other factors in a mother's decision to initiate breastfeeding. J Hum Lact. 2006; 22(1): 16-26, doi: 10.1177/0890334405283624, indexed in Pubmed: 16467284

12. Brown A. Maternal trait personality and breastfeeding duration: the importance of confidence and social support. J Adv Nurs. 2014; 70(3): 587-598, doi: 10.1111/jan.12219, indexed in Pubmed: 23919294.

13. Britton C, McCormick FM, Renfrew MJ, et al. Support for breastfeeding mothers. Cochrane Database Syst Rev. 2007(1): CD001141, doi: 10.1002/14651858.CD001141.pub3, indexed in Pubmed: 17253455.

14. Kaźmierczak M, Kiełbratowska B, Karasiewicz K. The other side of the mirror-the role of partner's empathy in transition to parenthood. Heal Psychol Rep. 2015; 3(2): 150-157, doi: 10.5114/hpr.2015.49649.

15. Schmied V, Beake S, Sheehan A, et al. Women's perceptions and experiences of breastfeeding support: a metasynthesis. Birth. 2011; 38(1): 49-60, doi: 10.1111/j.1523-536X.2010.00446.x, indexed in Pubmed: 21332775.
16. Dias CC, Figueiredo B. Breastfeeding and depression: a systematic review of the literature. J Affect Disord. 2015; 171: 142-154, doi: 10.1016/j. jad.2014.09.022, indexed in Pubmed: 25305429.

17. Figueiredo B, Dias CC, Brandão $S$, et al. Breastfeeding and postpartum depression: state of the art review. J Pediatr (Rio J). 2013; 89(4): 332-338, doi: 10.1016/j.jped.2012.12.002, indexed in Pubmed: 23791236.

18. Dennis CL, McQueen K. The relationship between infant-feeding outcomes and postpartum depression: a qualitative systematic review. Pediatrics. 2009; 123(4): e736-e751, doi: 10.1542/peds.2008-1629, indexed in Pubmed: 19336362.

19. Zawadzki B, Strelau J, Szczepaniak P. NEOFFI - Inwentarz Osobowości NEOFFI. Pracownia Testów Psychologicznych Polskiego Towarzystwa Psychologicznego, Warszawa 1998.

20. Łuszczyńska A, Mazurkiewicz M, Kowalska M, et al. Berlińskie Skale Wsparcia Społecznego (BSSS):Wyniki wstępnych badań nad adaptacją skal i ich własnościami psychometrycznymi. Stud Psychol. 2006; 44(3): 17-27.

21. O'Hara MW, McCabe JE. Postpartum depression: current status and future directions. Annu Rev Clin Psychol. 2013; 9:379-407, doi: 10.1146/annurev-clinpsy-050212-185612, indexed in Pubmed: 23394227.

22. Cox JL, Holden JM, Sagovsky R. Detection of postnatal depression. Development of the 10-item Edinburgh Postnatal Depression Scale. $\mathrm{Br}$ J Psychiatry. 1987; 150: 782-786, doi: 10.1192/bjp.150.6.782, indexed in Pubmed: 3651732.

23. Dennis CL. Can we identify mothers at risk for postpartum depression in the immediate postpartum period using the Edinburgh Postnatal Depression Scale? J Affect Disord. 2004; 78(2): 163-169, doi: 10.1016/s01650327(02)00299-9, indexed in Pubmed: 14706728.

24. Cattaneo A, Burmaz T, Arendt M, et al.'Promotion of Breastfeeding in Europe: Pilot Testing the Blueprint for Action'Project. Protection, promotion and support of breast-feeding in Europe: progress from 2002 to 2007. Public Health Nutr. 2010; 13(6): 751-759, doi: 10.1017/S1368980009991844, indexed in Pubmed: 19860992.

25. McFadden A, Gavine A, Renfrew MJ, et al. Support for healthy breastfeeding mothers with healthy term babies. Cochrane Database Syst Rev. 2017; 2: CD001141, doi: 10.1002/14651858.CD001141.pub5, indexed in Pubmed: 28244064.

26. Wallenborn JT, Ihongbe T, Rozario S, et al. Knowledge of Breastfeeding Recommendations and Breastfeeding Duration: A Survival Analysis on Infant Feeding Practices II. Breastfeed Med. 2017; 12: 156-162, doi: 10.1089/bfm.2016.0170, indexed in Pubmed: 28394658.

27. Smith HA, Becker GE. Early additional food and fluids for healthy breastfed full-term infants. Cochrane Database Syst Rev. 2016(8): CD006462, doi: 10.1002/14651858.CD006462.pub4, indexed in Pubmed: 27574798.

28. Żukowska-Rubik M. Dokarmianie dzieci karmionych piersią - kiedy, czym i jak? [Supplementation for breastfed infants - what to give, when and how? Stand Med Pediatr. 2013; 11: 189-199.

29. Pope CJ, Mazmanian D, Bédard M, et al. Breastfeeding and postpartum depression: Assessing the influence of breastfeeding intention and other risk factors. J Affect Disord. 2016; 200: 45-50, doi: 10.1016/j. jad.2016.04.014, indexed in Pubmed: 27126139.

30. Imširagić AS, Begić D, Sarajlić I, et al. Predictors of Exclusive Breastfeeding 6-9 Weeks After Delivery: a Prospective Cohort Study. Public Mental Health Perspective. Psychiatr Danub. 2016; 28(4): 395-403, indexed in Pubmed: 27855431.

31. World Health Organization, United Nations International Children's Emergency Fund. Background and implementation. Baby-friendly Hospital Initiative: Revised, updated and expanded for integrated care. In: The Global Criteria for BFHI Geneva, 2009.

32. Stuart AL, Pasco JA, Jacka FN, et al. Comparison of self-report and structured clinical interview in the identification of depression. Compr Psychiatry. 2014; 55(4): 866-869, doi: 10.1016/j.comppsych.2013.12.019, indexed in Pubmed: 24467941. 